\title{
PRODUÇÃO DE ZEÓLITAS A PARTIR DE CAULIM EM SISTEMA AGITADO COM AQUECIMENTO A VAPOR EM ESCALA SEMI-PILOTO
}

\author{
Rodrigues, E. C. ${ }^{(1)}$; Abreu, A. P. O.; ${ }^{(1)}$; Farias, B. M.; ${ }^{(1)}$; Macêdo, E. N. ${ }^{(1)}$; Souza, J. \\ A. S. ${ }^{(1)}$ \\ ${ }^{1}$ Universidade Federal do Pará( UFPA) \\ E-mail: ecr@ufpa.br
}

\begin{abstract}
RESUMO - O objetivo do trabalho é sintetizar Zeólita A em sistema agitado com aquecimento a vapor produzido por uma caldeira, a partir do rejeito de beneficiamento de caulim. Há um aspecto econômico muito importante, por possibilitar a transformação de um rejeito de baixo valor comercial em um material de elevado valor agregado (zeólita). Os materiais de partida e síntese das zeólitas foram caracterizados através de análise de Difração de Raios X e Microscopia Eletrônica de Varredura. No processo utilizou-se como fonte de sílica e alumínio o caulim calcinado, o qual foi calcinado à temperatura de $600^{\circ}$ por 2 horas em um forno cilíndrico e uma solução de $\mathrm{NaOH} 5 \mathrm{M}$. O tempo de reação para a formação do material zeolítico foi de 2 horas e a cada $30 \mathrm{~min}$ foi retirada uma alíquota para o estudo da cinética de formação das zeólitas. A calcinação do caulim formou o metacaulim, isto é, apenas a retirada da água da sua estrutura. A síntese produziu bons resultados, para formação de zeólitas tipo A. Também houve a formação de outra fase zeolítica, a hidroxisodalita, em função do tempo e do excesso de $\mathrm{NaOH}$ presente na reação.
\end{abstract}

Palavras-chave: caulim, metacaulim, zeólitas.

\section{INTRODUÇÃO}

No Pará estão localizadas três empresas de beneficiamento de caulim para cobertura de papel, a Caulim da Amazônia S.A. (CADAM), Pará Pigmentos S.A. (PPSA) e Imerys Rio Capim Caulim S.A. (IRCC), sendo suas reservas distribuídas nesse mesmo estado e no estado do Amapá, representando aproximadamente $70 \%$ das reservas brasileiras.

O beneficiamento de caulim gera uma grande quantidade de resíduo, porém tem uma grande importância sócio-econômica para o estado, provocando, dessa maneira perdas na qualidade ambiental. Esse rejeito é constituído essencialmente de caulinita, configurando-se em um material com grande potencial para ser usado em áreas, como construção civil (BARATA, 1998) e cerâmica (MARTELLI, 2006).

Esse trabalho visa utilizar esses resíduos para tentar minimizar os problemas ambientais e financeiros, pois como o mesmo é armazenado próximo à usina em lagoas de sedimentação, seria necessário desmatar grandes áreas, para que estas sejam formadas.

As Zeólitas são aluminossilicatos hidratados cristalinos de metais alcalinos e alcalinos terrosos. Sua estrutura é composta por um conjunto de cavidades ocupado por 
cátions e moléculas de água, ambas com liberdade de movimento, permitindo a troca iônica e hidratação reversível respectivamente (BRECK, 1973).

A procura de matérias-primas mais econômicas para a sintese de zeólitas resultou na utilização de argilominerais, dos quais o mais empregado é o caulim, por se tratar de um argilomineral que apresenta uma proporção de Si e Al muita parecida com a proporção encontrada na zeólita A (RODRIGUES, 2013).

Portanto, esse trabalho tem como proposta estudar a síntese de zeólitas a partir dos resíduos de mineração para tratar efluentes industriais.

O objetivo desse trabalho é a utilização de um rejeito de beneficiamento de caulim, como fonte de matéria prima na produção de zeólita A, mostrando que além de trazer benefícios de caráter ambiental, no sentido de redução do armazenamento desse rejeito, há um aspecto econômico muito importante, por possibilitar a transformação de um rejeito de baixo valor comercial em um material de elevado valor agregado (zeólita).

\section{MATERIAIS E MÉTODOS}

Como fonte de silício e alumínio foi utilizado rejeito de caulim, originado no processo de beneficiamento do caulim, produzido pela Imerys Rio Capim Caulim S/A IRCC, localizada no município de Barcarena, no estado do Pará. Sendo o caulim submetido a um processo de calcinação a $600^{\circ} \mathrm{C}$, em um forno tipo mufla por 2 horas no patamar de queima para a completa desidroxilação do material. A fonte de metal alcalino utilizada na síntese foi o $\mathrm{NaOH}$ sob a forma de uma solução a 5 molar.

\section{PROCESSO DE SÍNTESE}

O processo de síntese ocorreu através de duas etapas, sendo na primeira o caulim calcinado em mufla a $600^{\circ} \mathrm{C}$ por 2 horas (Figura 1), para ocorrer a desidroxilação do caulim, transformando em metacaulim. A segunda foi processada em uma autoclave de aço inox com 18 litros de volume, adicionando-se $1,5 \mathrm{Kg}$ de metacaulim a 3 litros de solução de $\mathrm{NaOH} 5$ molar. Posteriormente a autoclave foi aquecida a $110^{\circ} \mathrm{C}$ por um período de $2 \mathrm{~h}$, e retirada uma alíquota a cada 30 minutos. Após o período de reação e resfriamento da autoclave, a mistura reagente retirada a 30 minutos, 1 hora, 1hora e 30 minutos e de 2 horas foram filtradas para separação da zeólita obtida a qual foi submetida à lavagem com água destilada até o $\mathrm{pH}=7$ e posterior secagem em estufa a $110^{\circ} \mathrm{C}$ por 4 horas (Figura 2). 


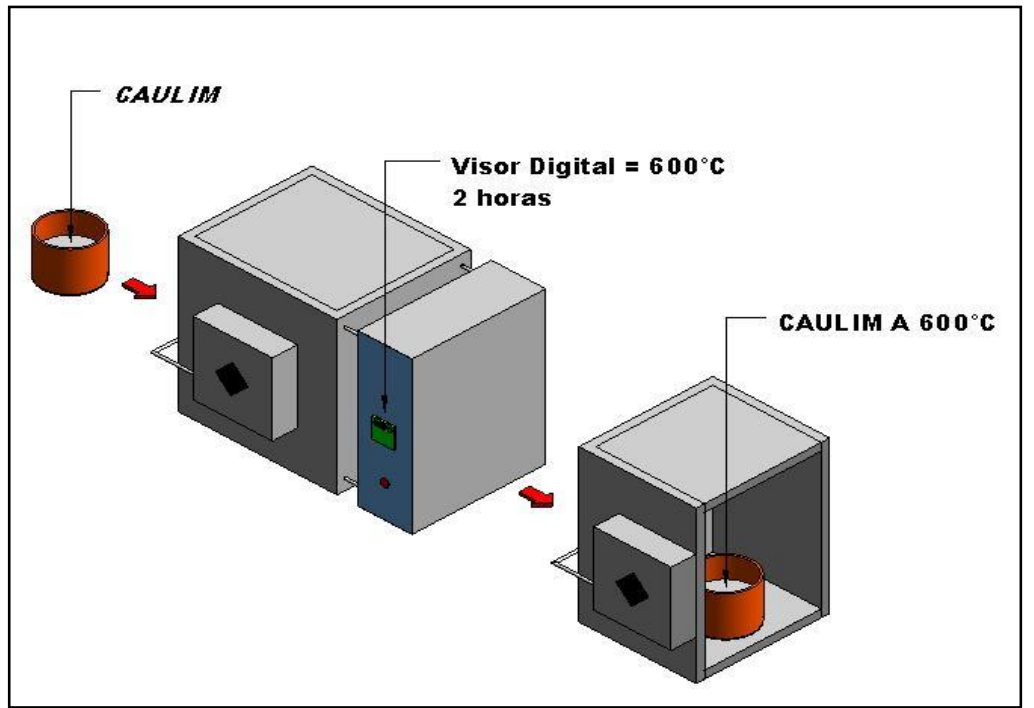

Figura 1 - Fluxograma do processo de calcinação do caulim em metacaulim.

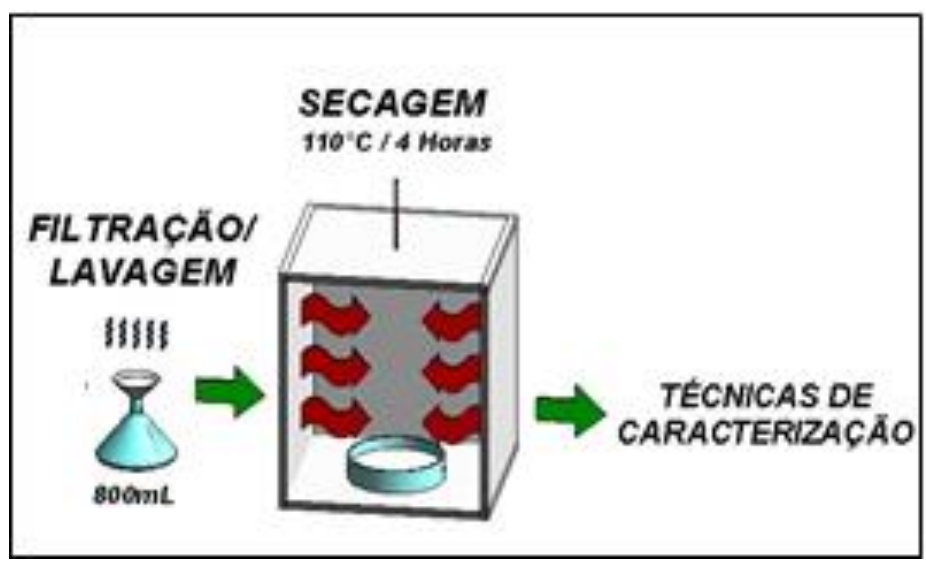

Figura 2 - Fluxograma do processo de filtração e secagem do material zeolítico.

\subsection{Processo de calcinação do caulim}

Para obter o metacaulim, a caulinita do rejeito de caulim foi tratada termicamente na temperatura de $600^{\circ} \mathrm{C}$ por $2 \mathrm{~h}$.

\section{TÉCNICAS DE CARACTERIZAÇÃO}

O material de partida e o produto de síntese foram caracterizados através de Difração de Raios- X (DRX) e Microscopia Eletrônica de Varredura.

\subsection{Difração de Raios $X$}

Para determinar a estrutura dos materiais cristalinos utiliza-se o método de Difração de Raios X. Um pequeno cristal do material, na ordem de uma fração de milímetro de tamanho, é mantido sob um feixe de raio X. Cada plano do átomo no cristal corresponde uma reflexão no difratograma. A posição de cada reflexão é registrada com sua intensidade em todo difratograma. 
Dessa maneira, desconsiderando o background (linha de base), o padrão de difração de uma determinada estrutura pode ser descrito em termos dos seguintes componentes: posição, intensidade e formas das múltiplas reflexões de Bragg.

\subsection{Microscopia eletrônica de varredura}

Para estudar a microestrutura, tamanho dos grãos, foram realizadas as análises por Microscopia eletrônica de varredura. Estas análises foram realizadas no Laboratório de Microscopia Eletrônica de Varredura do Instituto de Geociências da UFPA, utilizando-se um microscópio eletrônico de varredura da marca Zeiss (modelo LEO 1430) para a amostra do Caulim da Imerys Rio Capim Caulim S/A e do metacaulim.

\section{RESULTADOS E DISCUSSÕES}

A Figura 3 apresenta o difratograma de raios $\mathrm{X}$ do metacaulim, produto da calcinação do caulim, pode-se observar a transformação da caulinita em metacaulinita, ocasionada pelo completo rompimento da sua estrutura. Ainda são detectados picos de quartzo para o tempo utilizado na calcinação.

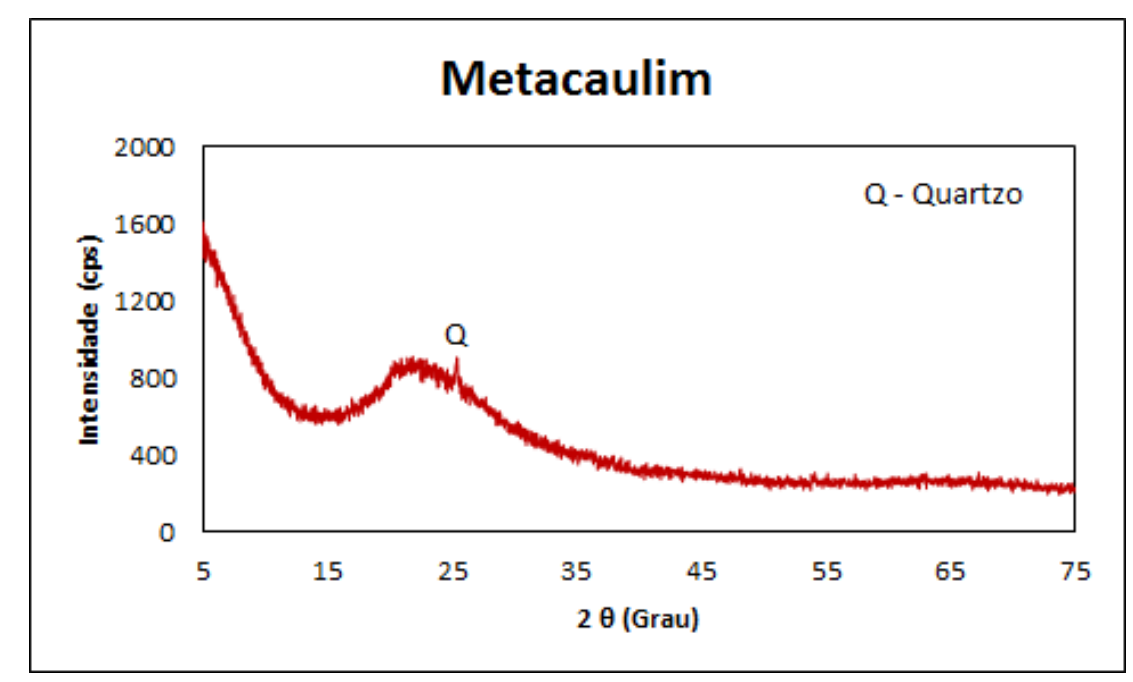

Figura 3 - Difração de raios X do metacaulim.

Os dados de Difração de Raios-X da Zeólita A são mostrados no difratograma da Figura 4. Pode se verificar os picos característicos da Zeólita A. Esse material também apresenta pequenos picos de hidroxisodalita nas quatro alíquotas retiradas a cada 30 minutos. 


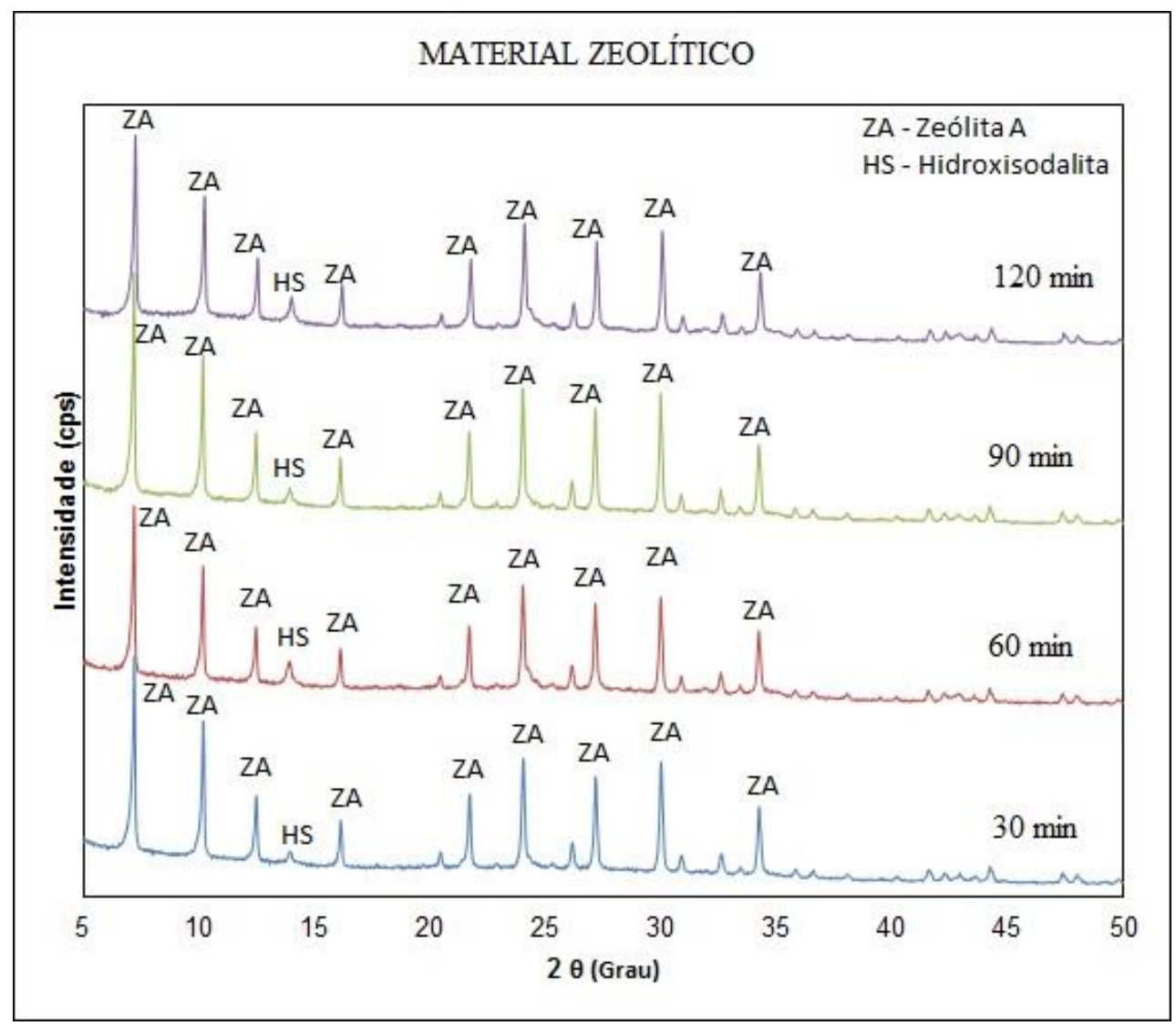

Figura 4 - Difratograma de raios X das zeólitas sintetizadas em 2 horas.

A Figura 5 apresenta a microscopia eletrônica de varredura do material zeolítico sintetizado, mostrando a morfologia cubica que é característica da zeolita $\mathrm{A}$, e também a morfologia esférica da hidroxisodalita.

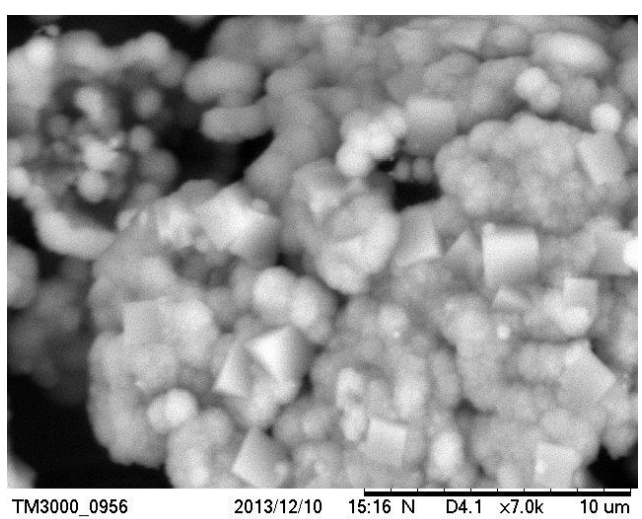

(a)

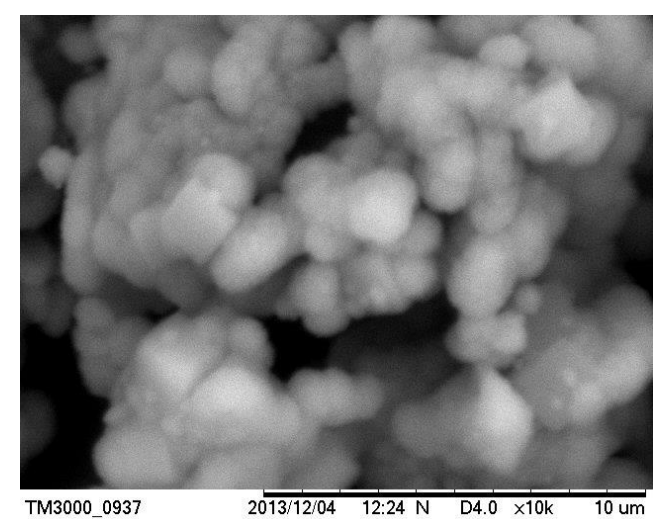

(b)

Figura 5 - (a) material zeolítico sintetizado no tempo de 60 minutos, (b) material zeolítico sintetizado no tempo de 120 minutos.

\section{CONCLUSÃO}

Com a utilização do rejeito de caulim (produzido pela Imerys Rio Capim Caulim S/A, obtido através do processo de delaminação) foi possível sintetizar através do processo hidrotérmico a zeólita A como a principal fase cristalina presente no material. Também foi obtido outra fase zeolítica denominada hidroxisodalita. 
Observou-se, em relação à calcinação do caulim, como fase principal, o metacaulim. Isto é, apenas a retirada da água da sua estrutura e a eliminação de impurezas presente. Em relação à morfologia dos cristais da Zeólita $\mathrm{A}$, produzida no processo, foram obtidos cristais na forma Cúbica, e hidroxisodalita na forma esférica.

\section{REFERÊNCIAS}

BRECK, D. B.; Zeolitic Molecular Sieves: structure, chemistry, and use. A Wiley Inter science publication, 1973.

HILDELBRANDO, E.A., Aplicação do Rejeito do Processo Bayer (Lama Vermelha) como Matéria-Prima na indústria de Cerâmica Estrutural. Dissertação (Mestrado em Engenharia Química - CMEQ/UFPa), Belém, 1998.

MAIA, A. A. B. Síntese da zeólita A utilizando como precursor um rejeito de benefiamento de caulim da Amazônia: aplicação com adsorvente. 2007. Dissertação (Mestrado em Engenharia Química) Universidade Federal do Pará. Belém, 2007.

MARTELLI, M. C. Transformações Térmicas e Propriedades Cerâmicas de Resíduos de Caulins das Regiões do Rio Capim e do Rio Jarí- Brasil. Tese (Doutorado emGeoquímica e Petrologia) apresentada ao Centro de Geociências da Universidade Federal do Pará. Belém, 2006.

MEIER, W. M.; Olson, D. H.; Atlas of Zeolite Structure Types, 3a. ed, ButterworthHeinemann, Londres, 1992.

FARIAS, B. M. Adsorção de Gases em Leito Fixo: Utilização de Resíduos da Indústria de Mineração (Resíduo de Caulim) como Adsorventes. Trabalho de iniciação cientifica em Engenharia Mecânica da Universidade Federal do Pará, 2013.

RODRIGUES, C. C.; Contribuição ao Estudo do tratamento do Gás Amoníaco por adsorção em Leito Fixo de Carvão Ativado. Tese (Doutorado em Engenharia Química) apresentada ao Programa da Pós-Graduação em Engenharia Química da Universidade Federal de São Carlos, São Carlos, 2002.

RODRIGUES, E. C. Reciclagem de Resíduo da Indústria de Beneficiamento de Caulim para a Produção de Zeólitas Utilizadas como Peneiras Moleculares. Trabalho de Conclusão de Curso em Engenharia Química da Universidade Federal do Pará, Belém, 2010. 